\title{
NUMERICAL SIMULATION OF THE HEATING PROCESS IN THE DOMAIN OF TISSUE INSULATED BY PROTECTIVE CLOTHING
}

\author{
Mariusz Ciesielski ${ }^{1}$, Bohdan Mochnacki ${ }^{2}$ \\ ${ }^{I}$ Institute of Computer and Information Sciences, Czestochowa University of Technology \\ Czestochowa, Poland \\ ${ }^{2}$ Higher School of Labour Safety Management, Katowice, Poland \\ ${ }^{l}$ mariusz.ciesielski@icis.pcz.pl, ${ }^{2}$ bmochnacki@wszop.edu.pl
}

\begin{abstract}
In this paper the 2D heterogeneous tissue domain (forearm cross-section) insulated by a layer of protective clothing is considered. The aim of considerations is to develop an algorithm simulating the tissue heating process resulting from the sudden change of external boundary conditions. Here, the authors exploit a certain version of the control volume method (CVM) using the Voronoi tessellation. The mathematical model of heat exchange in the domain analyzed is formulated in the form of a boundary-initial problem based on the system of partial differential equations (energy equations) supplemented by the adequate boundary and initial conditions. In the final part of the paper, the examples of numerical simulations are shown.
\end{abstract}

Keywords: bioheat transfer, protective clothing, modeling of thermal processes, control volume method, Voronoi tessellation

\section{Governing equations}

The cross-section of a forearm is shown in Figure 1 [1]. In the domain considered one can distinguish the sub-domains of different tissues and additionally the large blood vessels (arteries and veins).
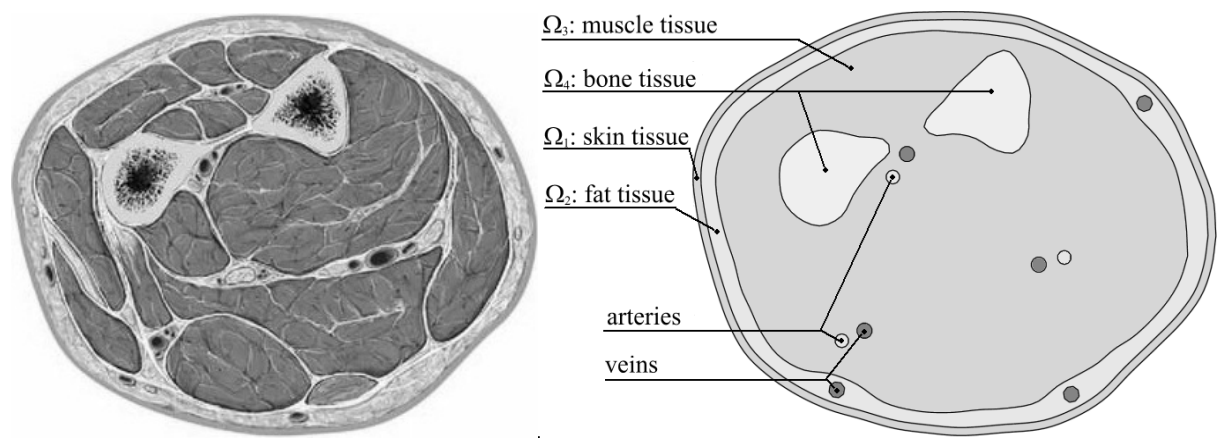

Fig. 1. Forearm cross-section and its geometrical model 
The thermal processes proceeding in the tissue sub-domains are described by the system of the Pennes equations

$$
c_{e}(T) \frac{\partial T_{e}(x, t)}{\partial t}=\nabla\left[\lambda_{e}(T) \nabla T_{e}(x, t)\right]+Q_{\text {pere }}(T)+Q_{\text {mete }}(T), \quad e=1, \ldots, 4
$$

where $e=1, \ldots, 4$ corresponds to skin, fat, muscle and bone sub-domains, $c_{e}$ is the volumetric specific heat, $\lambda_{e}$ is the thermal conductivity, $Q_{p e r}$ and $Q_{m e t}$ are the capacities of volumetric internal heat sources connected with the blood perfusion and metabolism $\left[\mathrm{W} / \mathrm{m}^{3}\right], T, x=\left\{x_{1}, x_{2}\right\}, t$ denote temperature, spatial co-ordinates and time.

Assuming that the tissue is fed by a large number of evenly spaced capillary blood vessels one has

$$
Q_{\text {per e }}(T)=c_{b} G_{b e}(T)\left[T_{b}-T_{e}(x, t)\right], \quad T_{b}=\left(T_{b \text { artery }}+T_{b \text { vein }}\right) / 2
$$

where $G_{b e}$ is the blood perfusion [ $\mathrm{m}^{3}$ blood/( $\mathrm{s} \mathrm{m}^{3}$ tissue $\left.)\right], c_{b}$ is the blood volumetric specific heat and $T_{b \text { artery }}$ and $T_{b \text { vein }}$ are the arterial and vein blood temperatures. The metabolic heat source $Q_{m e t}$ can be treated as a constant value or a temperaturedependent function [2].

On the contact surface between the tissue sub-domains the continuity of temperature and heat fluxes is assumed

$$
x \in \Gamma_{k-l}:\left\{\begin{aligned}
-\lambda_{k} \frac{\partial T_{k}(x, t)}{\partial n} & =-\lambda_{l} \frac{\partial T_{l}(x, t)}{\partial n}, \quad(k, l) \in\{(1,2),(2,3),(3,4)\} \\
T_{k}(x, t) & =T_{l}(x, t)
\end{aligned}\right.
$$

where $\partial / \partial n$ denotes a normal derivative.

The temperature field in the fabric region is described by the well-known Fourier equation

$$
c_{0}(T) \frac{\partial T_{0}(x, t)}{\partial t}=\nabla\left[\lambda_{0}(T) \nabla T_{0}(x, t)\right]
$$

where $c_{0}$ is the volumetric specific heat of fabric, $\lambda_{0}$ is the thermal conductivity.

Between the fabric and tissue the air gap (trapped air) should be taken into account and the continuity of heat flux leads to the following boundary condition

$$
x \in \Gamma_{0-1}: \quad-\lambda_{0} \frac{\partial T_{0}(x, t)}{\partial n}=\frac{T_{0}(x, t)-T_{1}(x, t)}{R(x, t)}=-\lambda_{1} \frac{\partial T_{1}(x, t)}{\partial n}
$$

where $R(x, t)$ is the trapped air thermal resistance. 
On the external surface of the system the Robin condition is assumed

$$
x \in \Gamma_{0}: \quad-\lambda_{0} \frac{\partial T_{0}(x, t)}{\partial n}=\alpha_{o u t}\left[T_{0}(x, t)-T_{\text {amb }}(t)\right]
$$

where $\alpha_{o u t}$ is the heat transfer coefficient, $T_{a m b}$ is the ambient temperature. The same type of boundary conditions is given on the contact surfaces between the blood vessels and soft tissue sub-domains, in particular

$$
x \in \Gamma_{\text {artery }}: \quad-\lambda_{3} \frac{\partial T_{3}(x, t)}{\partial n}=\alpha_{\text {artery }}\left[T_{3}(x, t)-T_{b \text { artery }}\right]
$$

and

$$
x \in \Gamma_{\text {vein }}: \quad-\lambda_{e} \frac{\partial T_{e}(x, t)}{\partial n}=\alpha_{\text {vein }}\left[T_{e}(x, t)-T_{b v e i n}\right], \quad e=\{2,3\}
$$

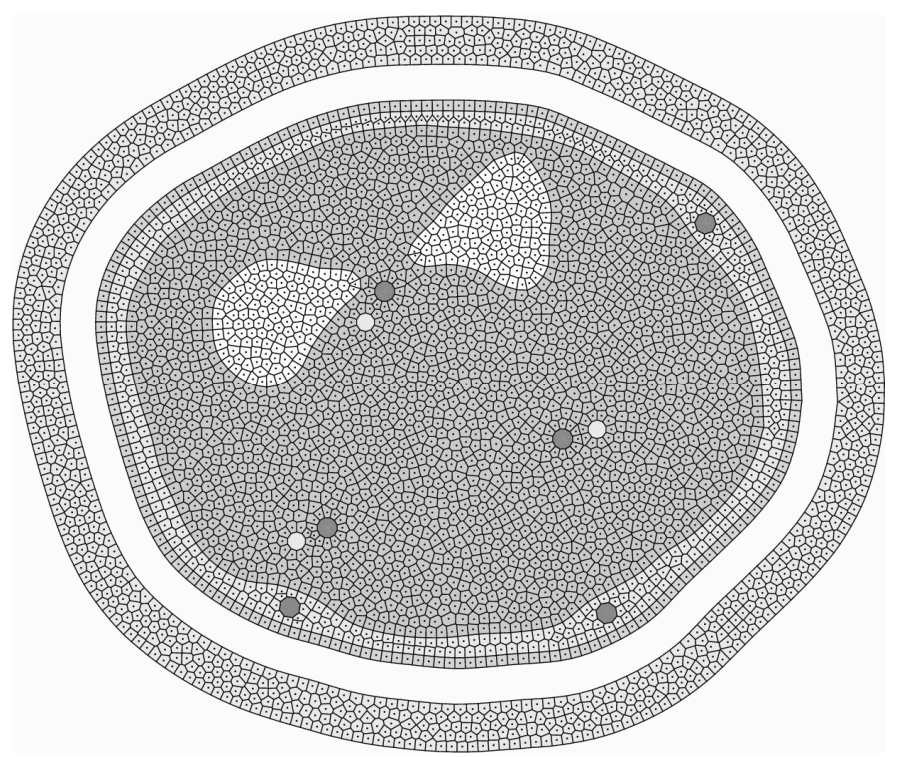

Fig. 2. Tissue and fabric sub-domains

The initial conditions are also given

$$
t=0: \quad T_{e}(x, t)=T_{0 e}(x), \quad e=0,1, \ldots, 4
$$

where $T_{0 e}$ is the initial temperature distribution. In this paper this distribution corresponds to the steady state conditions in the domain considered for the assumed ambient temperature and the assumed value of initial heat transfer coefficient $\alpha_{o u t}$. 
In Figure 2 the domain being the composition of tissue and fabric regions is shown (the domain discretization is also marked). The thickness of the air gap (according to literature [3]) in this region is equal to $0.5 \mathrm{~cm}$. From a theoretical point of view the thermal resistance of trapped air is a variable value, but the test computations show that the assumption of the constant value $R(x, t)=R$ is quite exact and acceptable.

\section{Control volume method}

At the stage of numerical modeling the control volume method using the Voronoi tessellation has been used. Such a version of CVM was discussed in detail by Ciesielski and Mochnacki in [4, 5]. Here, only the basic information concerning this variant of CVM will be presented. So, the domain analyzed is divided into $N$ volumes in the shape of Voronoi polygons (Fig. 3). The CVM algorithm allows one to find the transient temperature field at the set of nodes corresponding to the central points of the control volumes, and the nodal temperatures are found on the basis of energy balances for the successive CV.

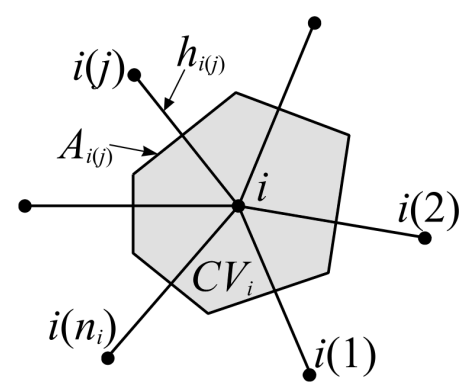

Fig. 3. Control volume $C V_{i}$

Let us consider control volume $C V_{i}$ with the central node $x_{i}$. It is assumed here that the thermal capacities and capacities of the internal heat sources are concentrated at the nodes representing elements, while the thermal resistances are concentrated on the sectors joining the nodes. The energy balances corresponding to the heat exchange between the analyzed control volume $C V_{i}$ and adjoining control volumes results from the integration of energy equation (e.g. (1)) with respect to time and volume $C V_{i}$. Let us consider the interval of time $\Delta t=t^{f+1}-t^{f}$. Then

$$
\begin{aligned}
\int_{t^{f}}^{t^{f+1}} \int_{C V_{i}} c_{e}(T) \frac{\partial T_{e}(x, t)}{\partial t} \mathrm{~d} V \mathrm{~d} t=\int_{t^{f}}^{t^{f+1}} & \int_{C V_{i}} \nabla\left[\lambda_{e}(T) \nabla T_{e}(x, t)\right] \mathrm{d} V \mathrm{~d} t \\
& +\int_{t^{f}}^{t^{f+1}} \int_{C V_{i}}\left[Q_{\text {pere }}(T)+Q_{\text {met }}(T)\right] \mathrm{d} V \mathrm{~d} t
\end{aligned}
$$


Using the Gauss-Ostrogradsky's theorem one obtains

$$
\begin{aligned}
\int_{t^{f}}^{t^{f+1}} \int_{C V_{i}} c_{e}(T) \frac{\partial T_{e}(x, t)}{\partial t} \mathrm{~d} V \mathrm{~d} t=\int_{t^{f}}^{t^{f+1}} \int_{A_{i}} \mathbf{n} \cdot\left[\lambda_{e}(T) \nabla T_{e}(x, t)\right] \mathrm{d} A \mathrm{~d} t \\
\\
+\int_{t^{f}}^{t_{C V_{i}}^{f+1}} \int_{\text {pere }}\left[Q_{\text {pet e }}(T)\right] \mathrm{d} V \mathrm{~d} t
\end{aligned}
$$

where $A_{i}$ is the surface (perimeter) limiting $C V_{i}$. The numerical approximation of the left-hand side of equation (11) can be accepted in the form

$$
\int_{t^{f}}^{t^{f+1}} \int_{C V_{i}} c_{e}(T) \frac{\partial T_{e}(x, t)}{\partial t} \mathrm{~d} V \mathrm{~d} t \cong c_{i}^{f}\left(T_{i}^{f+1}-T_{i}^{f}\right) \Delta V_{i}
$$

where $c_{i}^{f}$ is an integral mean of thermal capacity and this value is approximated by the volumetric specific heat corresponding to the temperature $T^{f}$ (explicit scheme). Similarly

$$
\int_{t^{f}}^{t^{f+1}} \int_{C V_{i}}\left(Q_{\text {pere }}(T)+Q_{\text {met e }}(T)\right) \mathrm{d} V \mathrm{~d} t \cong\left[\left(Q_{\text {per }}\right)_{i}^{f}+\left(Q_{\text {met }}\right)_{i}^{f}\right] \Delta V_{i} \Delta t
$$

The term determining heat conduction between $C V_{i}$ and its neighbourhoods can be written in the form

$$
\int_{t^{f}}^{t^{f+1}} \int_{A_{i}} \mathbf{n} \cdot\left[\lambda_{e}(T) \nabla T_{e}(x, t)\right] \mathrm{d} A \mathrm{~d} t \cong \sum_{j=1}^{n_{i}} \frac{T_{(j)}^{f}-T_{i}^{f}}{R_{i(j)}^{f}} A_{i(j)} \Delta t
$$

In the case of internal nodes

$$
R_{i(j)}^{f}=\frac{h_{i(j)}}{2 \lambda_{i}}+\frac{h_{i(j)}}{2 \lambda_{i(j)}}
$$

It can be shown that for the control volume $C V_{i}$ for which on the surface $A_{i(j)}$ the Robin condition is given

$$
R_{i(j)}^{f}=\frac{h_{i(j)}}{2 \lambda_{i}}+\frac{1}{\alpha}
$$

while for $C V_{i}$ for which on the surface $A_{i(j)}$ the continuity condition (5) is given

$$
R_{i(j)}^{f}=\frac{h_{i(j)}}{2 \lambda_{i}}+R+\frac{h_{i(j)}}{2 \lambda_{i(j)}}
$$


The energy balance (11) written in the 'explicit' form leads to the equation

$$
T_{i}^{f+1}=T_{i}^{f}+\sum_{j=1}^{n_{i}} W_{i(j)}\left(T_{i(j)}^{f}-T_{i}^{f}\right)+\frac{\Delta t}{c_{i}^{f}}\left[\left(G_{b}\right)_{i}^{f} c_{b}\left(T_{b}-T_{i}^{f}\right)+\left(Q_{m e t}\right)_{i}^{f}\right]
$$

where

$$
W_{i(j)}=\frac{A_{i(j)} \Delta t}{c_{i}^{f} R_{i(j)}^{f} \Delta V_{i}}
$$

The stability condition of explicit scheme

$$
1-\sum_{j=1}^{n_{i}} W_{i(j)}-\frac{\Delta t\left(G_{b}\right)_{i}^{f} c_{b}}{c_{i}^{f}}>0
$$

(for all control volumes $C V_{i}$ ) allows one to determine the critical time step.

\section{Example of numerical simulation}

The domain considered stays in the thermal contact with the environment whose temperature is equal to $T_{a}=20^{\circ} \mathrm{C}$, while the heat transfer coefficient between the fabric and environment $\alpha_{o u t}=3.7 \mathrm{~W} / \mathrm{m}^{2} \mathrm{~K}$. The initial temperature distribution corresponds to the solution of the steady state problem - Figure 4. Thermophysical parameters of successive sub-domains are taken from [6]. Additionally $T_{b \text { artery }}=$ $=36^{\circ} \mathrm{C}, T_{b \text { vein }}=35^{\circ} \mathrm{C}$, while $\alpha_{\text {artery }}=\alpha_{\text {vein }}=5000 \mathrm{~W} / \mathrm{m}^{2} \mathrm{~K}$. At the moment $t=0$ the ambient temperature increases to $70^{\circ} \mathrm{C}$ (heat transfer coefficient $\alpha_{\text {out }}=$ $\left.=100 \mathrm{~W} / \mathrm{m}^{2} \mathrm{~K}\right)$.

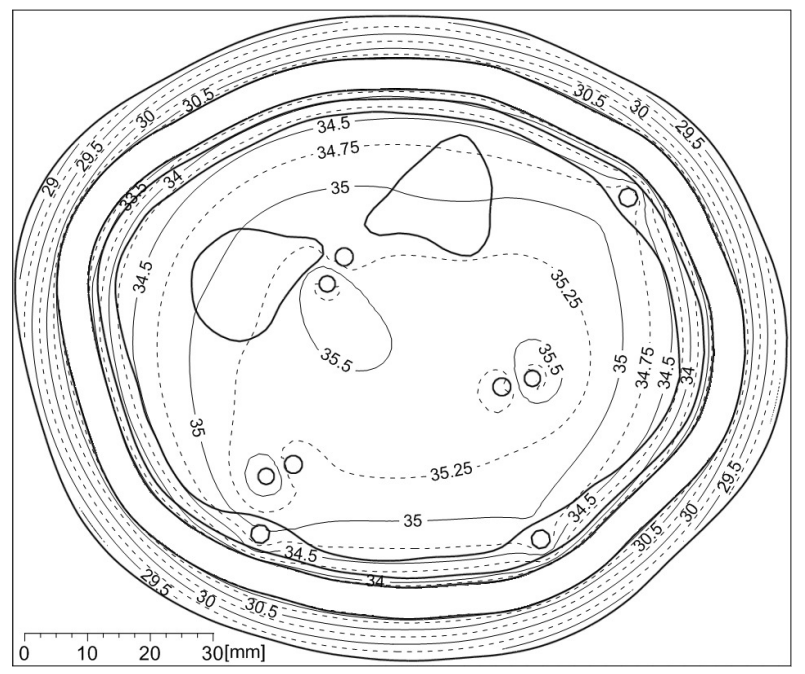

Fig. 4. Initial condition 
Figures 5 and 6 show the temperature distributions for time $1 \mathrm{~min}$ and $10 \mathrm{~min}$. One can see that for $t=10 \mathrm{~min}$ the skin tissue temperature is close to the temperature for which the burn wounds can appear and a prolonged stay in such environment is rather dangerous.

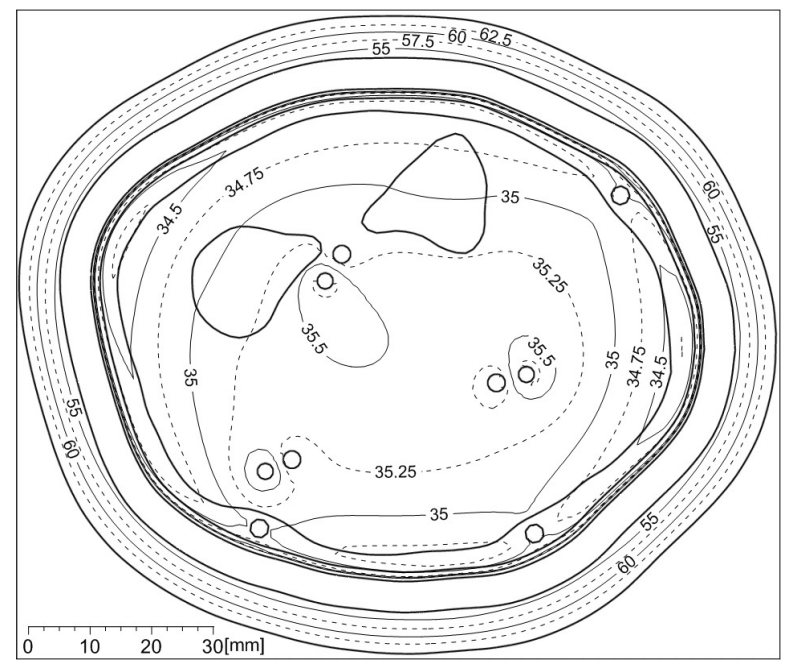

Fig. 5. Temperature distributions for time $1 \mathrm{~min}$

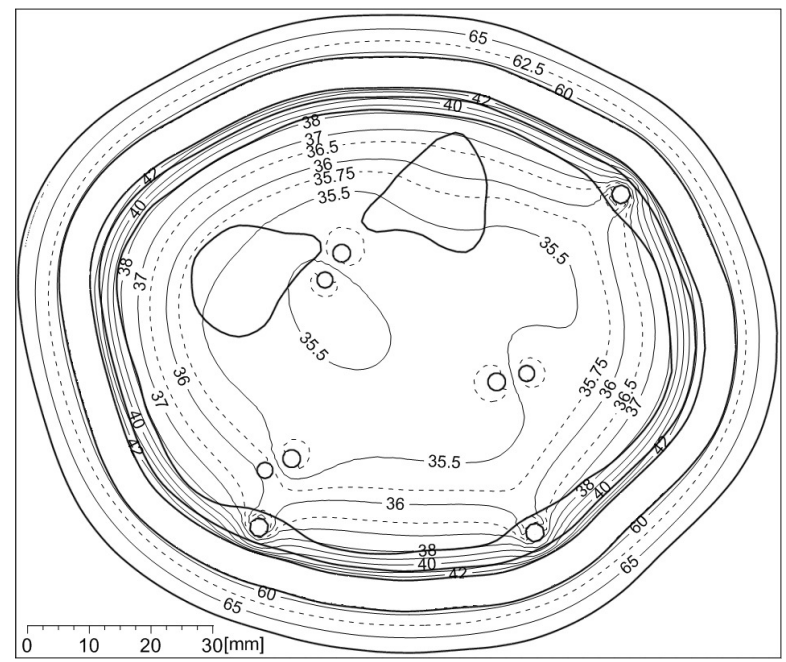

Fig. 6. Temperature distributions for time $10 \mathrm{~min}$

\section{Final remarks}

The main goal of the paper was to present the possibilities of the CVM application (in the version discussed) for numerical solution of the bio-heat transfer 
problems. The essential advantage of the method proposed is the fact that the shape and location of tissue sub-domains can be accurately reproduced (if the assumption of $2 \mathrm{D}$ approximation is acceptable). Additionally, the Voronoi polygons assure the good approximation of energy balances (11). The problem of boundary conditions joining is also very simple. The mathematical model used here belongs to the group of the so-called tissue models based on the Pennes equation. The typical feature of this approach is the introduction of additional terms corresponding to perfusion and metabolic heat sources to the energy equation. The method presented can be used for numerical modeling of different problems from the scope of medical practice (e.g. simulation of cryosurgical treatments).

\section{Acknowledgement}

The paper is a part of Project PB3/2013 sponsored by WSZOP Katowice.

\section{References}

[1] Ciesielski M., Mochnacki B., Application of the Control Volume Method using the Voronoi polygons for numerical modeling of bio-heat transfer processes, Journal of Theoretical and Applied Mechanics (in print).

[2] Majchrzak E., Modelowanie i analiza zjawisk termicznych, cz. IV, [in:] Mechanika Techniczna, tom XII: Biomechanika, pod red. R. Będzińskiego, IPPT PAN, Warszawa 2011, 223-361.

[3] Chitrphiromsri P., Modeling of thermal performance of firefighter protective clothing during the intense heat exposure, Mechanical Engineering, Doctoral Theses, Raleigh 2004.

[4] Domanski Z., Ciesielski M., Mochnacki B., Applications of control volume method using the Voronoi tessellation in numerical modeling of solidification process, [in:] Current Themes in Engineering Science 2009, A. Korsunsky (ed.), American Institute of Physics Conf. Proc. 2010, 1220, 17-26.

[5] Mochnacki B., Ciesielski M., Application of Thiessen polygons in control volume model of solidification, Journal of Achievements in Materials and Manufacturing Engineering 2007, 23(2), 75-78.

[6] Fiala D., Lomas K.J., Stohrer M., A computer model of human thermoregulation for a wide range of environmental conditions: the passive system, Journal of Applied Physiology 1999, 87, 5, 1957-1972. 